\title{
Med1 regulates meiotic progression during spermatogenesis in mice
}

\author{
Jessica M Huszar ${ }^{1}$, Yuzhi Jia ${ }^{2}$, Janardan K Reddy ${ }^{2}$ and Christopher J Payne ${ }^{1,3}$ \\ ${ }^{1}$ Driskill Graduate Program, ${ }^{2}$ Department of Pathology and ${ }^{3}$ Departments of Pediatrics and Obstetrics and \\ Gynecology, Northwestern University Feinberg School of Medicine and Human Molecular Genetics Program, \\ Stanley Manne Children's Research Institute, Ann and Robert H. Lurie Children's Hospital of Chicago, \\ 225 E Chicago Avenue, PO Box 211, Chicago, Illinois 60611, USA
}

Correspondence should be addressed to CJ Payne; Email: c-payne@northwestern.edu

\begin{abstract}
Spermatogenesis is a highly coordinated process. Signaling from nuclear hormone receptors, like those for retinoic acid (RA), is important for normal spermatogenesis. However, the mechanisms regulating these signals are poorly understood. Mediator complex subunit 1 (MED1) is a transcriptional enhancer that directly modulates transcription from nuclear hormone receptors. MED1 is present in male germ cells throughout mammalian development, but its function during spermatogenesis is unknown. To determine its role, we generated mice lacking Med1 specifically in their germ cells beginning just before birth. Conditional Med1 knockout males are fertile, exhibiting normal testis weights and siring ordinary numbers of offspring. RA-responsive gene products stimulated by RA gene 8 (Stra8) and synaptonemal complex protein 3 (Sycp3) are first detected in knockout spermatogonia at the expected time points during the first wave of spermatogenesis, and persist with normal patterns of cellular distribution in adult knockout testes. Meiotic progression, however, is altered in the absence of Med1. At postnatal day 7 (P7), zygotene-stage knockout spermatocytes are already detected, unlike in control testes, with fewer pre-leptotene-stage cells and more leptotene spermatocytes observed in the knockouts. At P9, Med1 knockout spermatocytes prematurely enter pachynema. Once formed, greater numbers of knockout spermatocytes remain in pachynema relative to the other stages of meiosis throughout testis development and its maintenance in the adult. Meiotic exit is not inhibited. We conclude that MED1 regulates the temporal progression of primary spermatocytes through meiosis, with its absence resulting in abbreviated pre-leptotene, leptotene, and zygotene stages, and a prolonged pachytene stage.

Reproduction (2015) 149 597-604
\end{abstract}

\section{Introduction}

Spermatogenesis is a tightly regulated process driven by a complex network of germ cell-autonomous gene transcription and extrinsic signaling from supporting somatic cells. In adult mice, seminiferous tubules contain layers of germ cells at different developmental stages. On the basis of the composition of germ cells in a given tubule cross-section the mouse seminiferous epithelial cycle consists of 12 distinct stages (Oakberg 1956). The germ cells develop through these stages in a spatiotemporally coordinated manner, resulting in constant sperm production. Progression of a cohort of germ cells through seminiferous epithelial cycles until they are released into the epididymis is referred to as a spermatogenic wave (Perey et al. 1961).

Ligands of nuclear hormone receptors have long been known to play an important role in spermatogenesis. Mice with deficiencies in vitamin A and vitamin D have impaired fertility (Howell et al. 1963, Thompson et al.
1964, Jensen 2014). Vitamin A is metabolized to retinoic acid (RA), and thus RA signaling is a readout for vitamin A levels. $R A$ is required for spermatogonial differentiation as well as for meiotic entry (Van Pelt \& De Rooij 1990, Zhou et al. 2008, Barrios et al. 2010). The male germ cells express a number of nuclear hormone receptors in a development-specific manner. RA receptors $\gamma$ (RARG) and $\alpha$ (RARA) function in undifferentiated spermatogonia (Vernet et al. 2006, Gely-Pernot et al. 2012). Mice with either a global or a germ cell-specific RARG and RARA ablation have an increased number of degenerative seminiferous tubules with no mature germ cells, due to a block in spermatogonial differentiation (Gely-Pernot et al. 2012). The vitamin D receptor (VDR) is highly expressed in male germ cells (Jensen 2014). VDR-null mice are infertile and have abnormal histology, although the precise mechanisms are unknown (Kinuta et al. 2000).

Mediator is a large multi-protein complex that functions as a transcriptional enhancer. Mediator complex subunit 1 (MED1) specifically interacts with 
nuclear hormone receptors, including RARs and VDR, to activate target genes (Zhu et al. 1997, Yuan et al. 1998, Ren et al. 2000, Urahama et al. 2005). MED1 promotes nuclear hormone receptor-mediated transcription in a ligand-dependent manner through an interaction between the LxxLL motif of MED1 and the AF2 domain of the receptor (reviewed in Chen \& Roeder (2011)). The global knockout of Med1 in mice is embryonic lethal in mid-gestation (Ito et al. 2000, Zhu et al. 2000). Conditional knockouts have revealed numerous roles for Med1 in the regulation of cell differentiation and lineage specification, including myelomonocytic differentiation, erythroid development, mammary luminal epithelial cell determination, and hair differentiation (Urahama et al. 2005, Jiang et al. 2010, Stumpf et al. 2010, Oda et al. 2012).

Previous work by us demonstrated that Med 1 is highly expressed throughout male germ cell development (Huszar \& Payne 2013). However, the functional role of Med1 in spermatogenesis is unknown. Due to the role of MED1 in the promotion of nuclear hormone receptormediated gene transcription, we hypothesized that MED1 may play a role in regulating the onset and duration of spermatogonial differentiation. To this end, we generated mice with a conditional germ cell-specific ablation of Med1. Unexpectedly, our results establish a novel role for Med1 in regulating the dynamics of meiotic progression, modulating the amount of time spermatocytes exist in leptonema, zygonema and pachynema.

\section{Materials and methods}

\section{Mice}

All procedures and care of animals were carried out in accordance with the Stanley Manne Children's Research Institute Animal Care and Use Committee (Manne IACUC). The Manne IACUC specifically approved this study, protocol \#13-002.0. Generation of floxed Med1 mice has been described previously (Jia et al. 2004). Germ cell-specific Med1 knockout mice were generated by crossing hemizygous FVB- $\mathrm{Tg}(D d \times 4$-cre $) 1 \mathrm{Dcas} / \mathrm{J}$ mice (referred to here as Vasa-cre) with floxed C57BL/6 Med $1^{f / f t}$ mice to generate Vasa-cre ${ }^{+} ; M e d 1^{f l+} F_{1}$ mice. These mice were then crossed with additional Medf $1^{f l / f l}$ to generate Vasa-cre ${ }^{+}$; Med $1^{\Delta / f l} \mathrm{~F}_{2}$ mice. Control mice used were Vasa-cre ${ }^{-} ;$Med $1^{\Delta / f l}$ or Vasa-Cre ${ }^{+} ; \mathrm{Med1}^{f /++}$. Genotyping was performed using PCR on genomic DNA. PCR primer sequences are available upon request. Vasa-cre mice were obtained from the Jackson Laboratory (Bar Harbor, ME, USA). Testis weights and body weights were measured when mice were killed. To assess the fertility of knockout mice, 10-week-old male mice were backcrossed with WT female mice for a period of 5 months, and the number of pups generated through such matings was evaluated.

\section{Histology and immunohistochemistry}

The testes were fixed with Bouin's solution at $4{ }^{\circ} \mathrm{C}$, and dehydrated for paraffin embedding. The sections were cut to a thickness of $5 \mu \mathrm{M}$, deparaffinized, and rehydrated. For histology, sections were stained with hematoxylin and eosin $(\mathrm{H}+\mathrm{E})$. For immunohistochemistry (IHC), slides were prepared by performing antigen retrieval. The slides were boiled in $0.01 \mathrm{M}$ sodium citrate, $\mathrm{pH} 6.0$, for $10 \mathrm{~min}$. The sections were then blocked for $1 \mathrm{~h}$ at room temperature with $3 \%$ goat serum in PBS. The sections were incubated overnight at $4{ }^{\circ} \mathrm{C}$ with primary antibodies diluted in $3 \%$ goat serum in PBS. The primary antibodies used for IHC were anti-SYCP3 (\#ab15093, Abcam, Cambridge, MA, USA), anti- $\gamma \mathrm{H} 2 \mathrm{AX}$ (\#05-636, Millipore, Billerica, MA, USA), anti-STRA8 (\#ab49602, Abcam), anti-MED1 (\#ab64965, Abcam), antiTRA98 (\#ab82527, Abcam), anti-BOULE (gift of Eugene Xu, Northwestern University), and anti-SOHLH1 (gift of Aleksandar Rajkovic, University of Pittsburgh). The sections were then labeled with the appropriate fluorescenceconjugated secondary antibody for $1 \mathrm{~h}$ at room temperature. The slides were incubated for $10 \mathrm{~min}$ with 4',6-diamidino2-phenylindole (DAPI). The coverslips were then affixed with Vectashield anti-fade mounting medium (Vector Laboratories, Burlingame, CA, USA) and samples were imaged using a Leica DMR-HC epifluorescence microscope with $10 \times$, $20 \times$, and $40 \times$ objectives and a QImaging Retiga 4000R camera (Surrey, BC, Canada).

\section{Chromosome spreads}

Chromosome spreads were prepared from testis following methods reported previously (Peters et al. 1997). Briefly, the tunica albuginea was removed from testes at postnatal days P7, P14, P28, and 6-weeks-old, and the seminiferous tubules were placed in a hypotonic extraction buffer containing $30 \mathrm{mM}$ Tris, $50 \mathrm{mM}$ sucrose, $17 \mathrm{mM}$ trisodium citrate dehydrate, $5 \mathrm{mM}$ EDTA, and $0.5 \mathrm{mM}$ phenylmethylsulfonyl fluoride at $\mathrm{pH} 8.2$ for $60 \mathrm{~min}$. A $20 \mu \mathrm{l}$ drop of $100 \mathrm{mM}$ sucrose at $\mathrm{pH} 8.2$ was placed on a clean glass slide. A small section of a seminiferous tubule was placed in the sucrose and minced using fine forceps. An additional $20 \mu \mathrm{l}$ of $100 \mathrm{mM}$ sucrose was added and the cells were pipetted to create a suspension. The suspension was spread across two new slides that had been cleaned in $1 \%$ paraformaldehyde with $0.15 \%$ Triton X-100. The cells were allowed to dry for $4 \mathrm{~h}$ at room temperature with high humidity. The slides were then rinsed twice in $0.4 \%$ Photoflo (Kodak). To prepare slides for imaging, slides were blocked with $5 \%$ goat serum in PBS for $1 \mathrm{~h}$ at room temperature. They were then incubated overnight at $4{ }^{\circ} \mathrm{C}$ with anti-SYCP3 and anti- $\gamma \mathrm{H} 2 \mathrm{AX}$. Finally, the slides were incubated with secondary antibodies and imaged. The cells were incubated for 10 min with DAPI and then coverslips were attached with Vectashield (Vector Laboratories). Chromosome spreads were made from three mice of each genotype.

\section{Statistical analyses}

All experiments were performed at least three times. Data are presented as the mean \pm s.E.M. Statistical analyses were carried out using Prism 5 GraphPad Software (La Jolla, CA, USA). Significance between the means was determined using Student's t-test. 
A

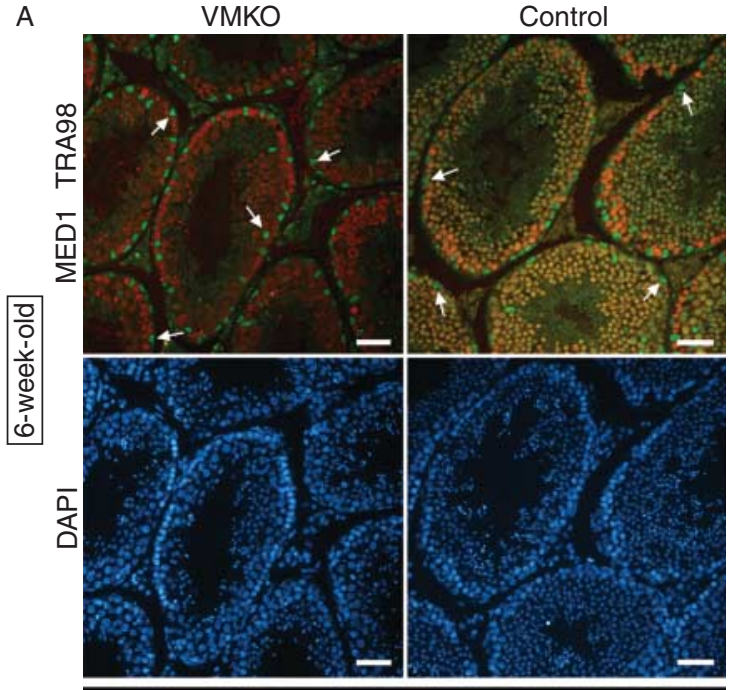

B
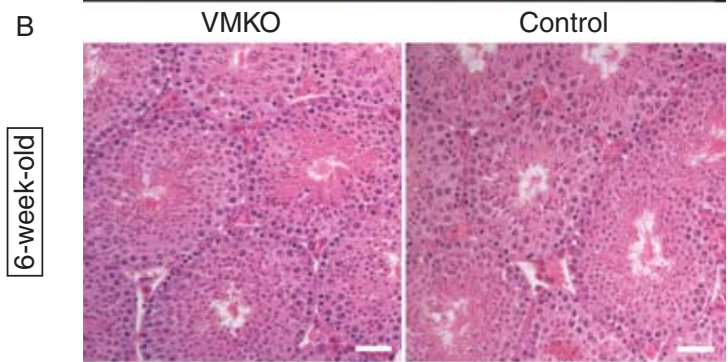

C

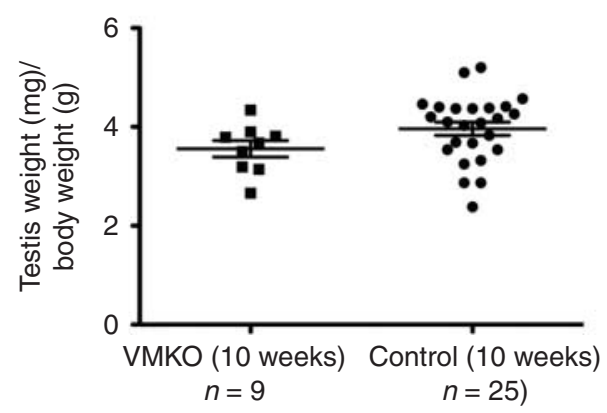

Figure 1 Vasa-cre-mediated Med1 knockout (VMKO) testes exhibit normal morphology and weight. (A) Cross-sections of 6-week-old VMKO (left) and control (right) testes immunostained for MED1 (green) and the pan-germ cell marker TRA98 (red), and exposed to DNA stain DAPI (blue). Arrows identify Sertoli cell nuclei positive for MED1 but negative for TRA98. Scale bars $=50 \mu \mathrm{m}$. (B) Cross-sections of 6-weekold VMKO (left) and control (right) testes stained with hematoxylin and eosin. Scale bars $=50 \mu \mathrm{m}$. (C) Assessment of testis weight:body weight measurements of 10-week-old VMKO (left, $n=9$ ) and control (right, $n=25$ ) male mice. Differences are not statistically significant (Student's $t$-test).

\section{Results}

\section{Med1 ablation in fetal prospermatogonia does not impact fertility in adult male mice}

To examine the role that Med1 plays in the developing male germ line, we generated germ cell-specific Med1 knockout mice by intercrossing floxed Med1 mice with Vasa-cre mice. These Vasa-cre;Med $1^{\Delta / f l}$ mice are referred to here as Vasa-cre mediated-Med1 knock out (VMKO) animals. Vasa-cre is specifically expressed in germ cells beginning at embryonic day 15 (Gallardo et al. 2007). To validate that Med1 was only ablated in germ cells, 6-week-old VMKO mice testes were examined for the co-distribution of MED1 and germ cell-specific antigen TRA98 (Tanaka et al. 1997). We did not detect any MED1 in VMKO germ cells (Fig. 1A). Only Sertoli cells and testicular interstitial cells contained MED1 in the conditional knockout samples. Histological examination of 6-week-old VMKO testes did not reveal any abnormalities. Hematoxylin and eosin staining revealed an appearance of VMKO cross-sections that was comparable with control sections (Fig. 1B). Testis weights and body weights were measured from VMKO and control animals. No differences were seen in the VMKO body weights $(25.8 \mathrm{~g}$ mean average $\pm 0.92 \mathrm{~g}$ S.E.M. vs $24.1 \mathrm{~g}$ mean average $\pm 0.74 \mathrm{~g}$ S.E.M. in controls) or in the testis weights (95.6 $\mathrm{mg}$ mean average $\pm 4.94 \mathrm{mg}$ S.E.M. vs $95.2 \mathrm{mg}$ mean average $\pm 4.07 \mathrm{mg}$ S.E.M. in controls), resulting in statistically similar testis weight:body weight ratios (Fig. 1C). We next examined the fertility of male mice lacking Med1 in their germ cells. Ten-week-old VMKO males were mated with WT females continuously for 5 months. VMKO males were fertile with normal litter sizes (Fig. 2A) and a normal accumulation of successive

A

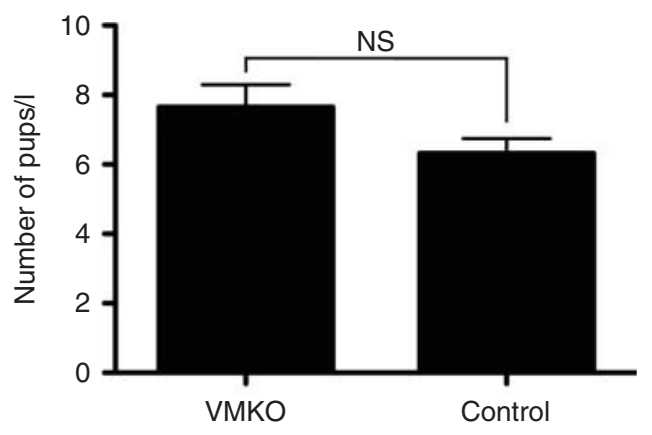

B

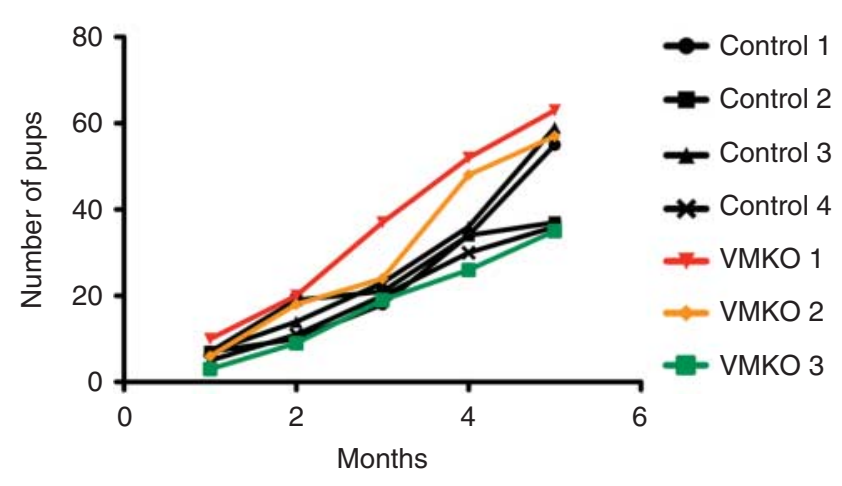

Figure 2 VMKO male mice exhibit normal fertility. (A) VMKO and control males were mated with WT female mice for a period of 5 months. Average litter size for each group is shown. Graph exhibits mean values \pm s.E.M. Difference is not statistically significant (NS, Student's $t$-test). (B) The cumulative number of pups sired by each animal over the entire breeding period. 
litters (Fig. 2B). From these data, we conclude that VMKO animals produce sperm and exhibit normal fertility.

\section{Male germ cells lacking Med1 exhibit normal STRAB and SYCP3 localization but display altered meiotic progression}

Because MED1 interacts with nuclear hormone receptors in many different cell types, we evaluated the cross-sections of adult VMKO testes for distribution patterns of RA-responsive gene products. The levels of two proteins, stimulated by RA gene 8 (STRA8) and synaptonemal complex protein 3 (SYCP3), increase in male germ cells upon exposure to RA (Snyder et al. 2011, Busada et al. 2014). Upregulation of Stra8 occurs through the direct engagement of response elements near the gene by activated RARs (Raverdeau et al. 2012, Kumar et al. 2013), while the increase in Sycp3 expression happens in a RAR-independent manner (Tedesco et al. 2013). Nonetheless, SYCP3 is an excellent marker of RA-induced differentiation. In 6-week-old VMKO testes, both STRA8 and SYCP3 appropriately localized to differentiating spermatogonia and meiotic spermatocytes (Fig. $3 \mathrm{~A}$ and B). Equivalent numbers of STRA ${ }^{+}{ }^{+}$and SYCP ${ }^{+}{ }^{+}$cells were detected in the cross-sections of VMKO seminiferous tubule when compared with controls (Fig. 3A, B, and C). Since adult testes reflect steady-state spermatogenesis, we next wondered whether the first-wave spermatogenic cells in developing $\mathrm{VMKO}$ testes exhibited distribution patterns of STRA8 and SYCP3 comparable with control testes. Endogenous RA signaling usually commences in male germ cells beginning at postnatal day 3 (P3) or P4 (Zhou et al. 2008, Snyder et al. 2010). When P2 testes were examined for STRA8, indeed both VMKO and control samples completely lacked STRA ${ }^{+}$cells in their seminiferous tubules (Fig. 4A). By contrast, P4 testes from $\mathrm{VMKO}$ and control animals exhibited STRA $8^{+}$cells in equivalent numbers (Fig. $4 \mathrm{~A}$ and $\mathrm{B}$ ). This finding suggests that there is no premature RA signaling response occurring in male germ cells lacking Med1.

Spermatogonia committing to differentiation upregulate spermatogenesis- and oogenesis-specific basic helixloop-helix-containing protein 1 (SOHLH1; Suzuki et al. 2012). This protein is essential for mitotic germ cell differentiation before entering meiosis (Ballow et al. 2006). P7 testes from VMKO males exhibited SOHLH1 ${ }^{+}$ cells at numbers comparable with those in controls (Fig. 4B and C), indicating that the initial wave of spermatogonial differentiation is not disrupted in the absence of MED1. Subsequently, the first set of male germ cells enters the pre-leptotene and leptotene stages of meiosis in mice between P7 and P9, prompting our examination of VMKO testes for SYCP3 at this time window. At P9, cross-sections of VMKO testis reveal an abundant number of $\mathrm{SYCP}^{+}$cells that is indistinguishable in scope from control sections (Fig. 4C). This pattern

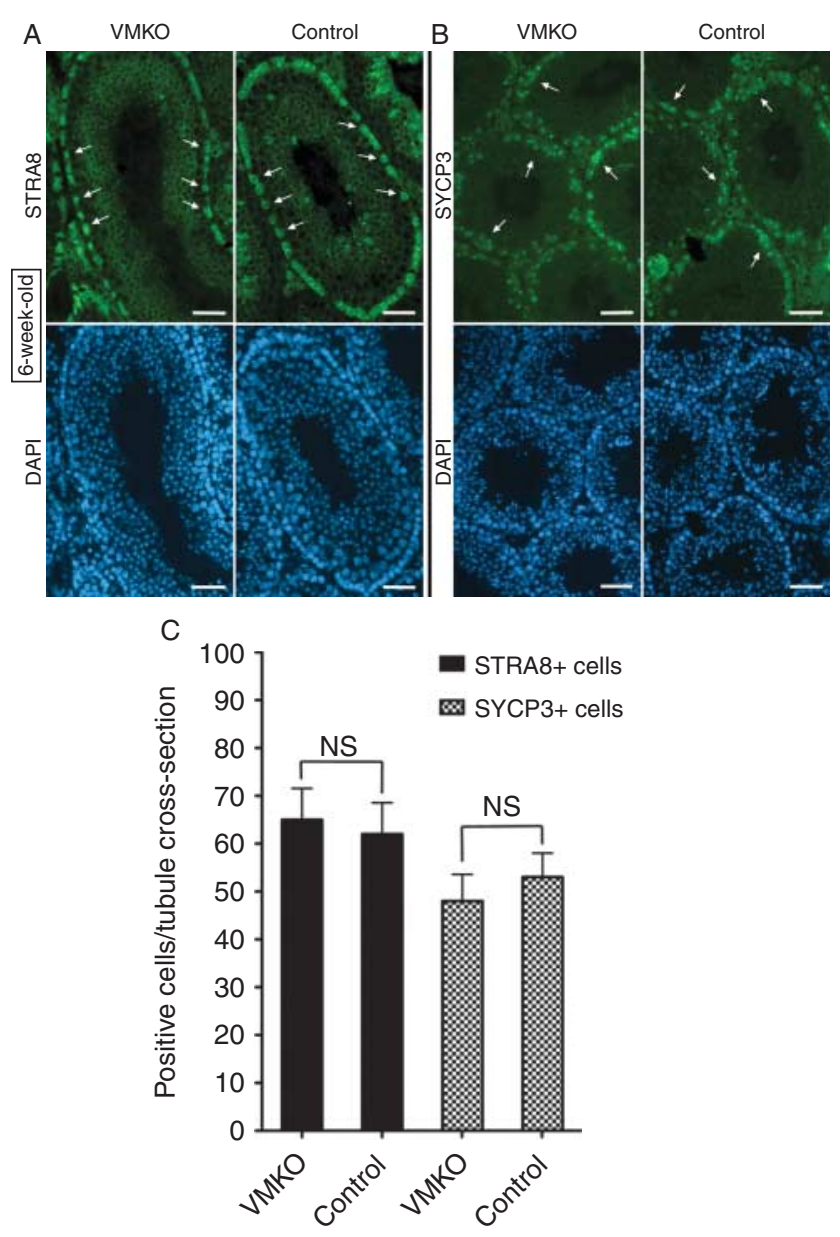

Figure 3 Adult VMKO testes contain normal numbers of retinoic-acid responsive germ cells. (A) Cross-sections of 6-week-old VMKO (left) and control (right) testes immunostained for STRA8 (green) and exposed to DAPI (blue). Arrows identify STRA8-positive cells. Scale bars $=50 \mu \mathrm{m}$. (B) Cross-sections of 6-week-old VMKO (left) and control (right) testes immunostained for SYCP3 (green) and exposed to DAPI (blue). Arrows identify SYCP3-positive cells. Scale bars $=50 \mu \mathrm{m}$. (C) Quantitation of STRA $8{ }^{+}$and $\mathrm{SYCP}^{+}{ }^{+}$cells per seminiferous tubule cross-section in 6-week-old VMKO and control testes. Graph exhibits mean values \pm s.E.M. Differences are not statistically significant (NS, Student's $t$-test).

persists at P12, with both VMKO and control samples containing equivalent numbers of $\mathrm{SYCP}^{+}{ }^{+}$cells (Fig. 4C).

We next prepared chromosome spreads from VMKO testes, beginning at P7, to more closely evaluate the meiotic stages represented in the samples. The spreads were co-stained for SYCP3 and $\mathrm{H} 2 \mathrm{~A}$ histone family, member $X(\mathrm{H} 2 \mathrm{AFX} ; \gamma \mathrm{H} 2 \mathrm{AX})$, which allowed us to determine the specific stage of prophase I (Ashley 2004). At P7, we observed zygotene-stage spermatocytes in the testes of VMKO males but not in control males (Fig. 5A). At P9, we detected pachytene-stage spermatocytes in VMKO but not in control testes (Fig. 5B), reflecting a premature progression through prophase I of meiosis. When the overall percentage of SYCP3 ${ }^{+}$cells in 

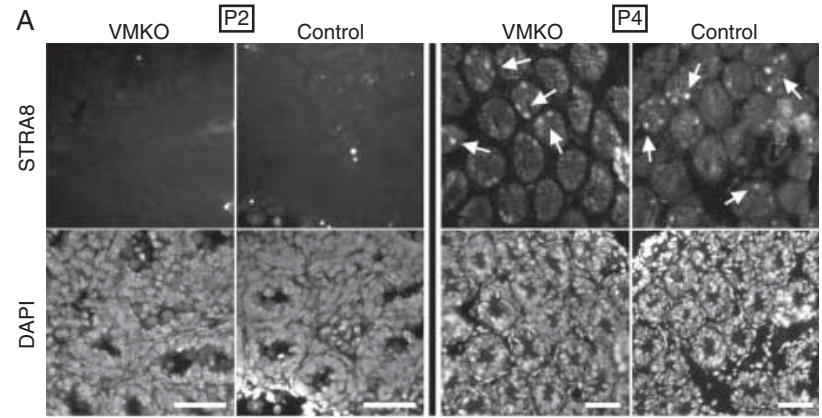

B
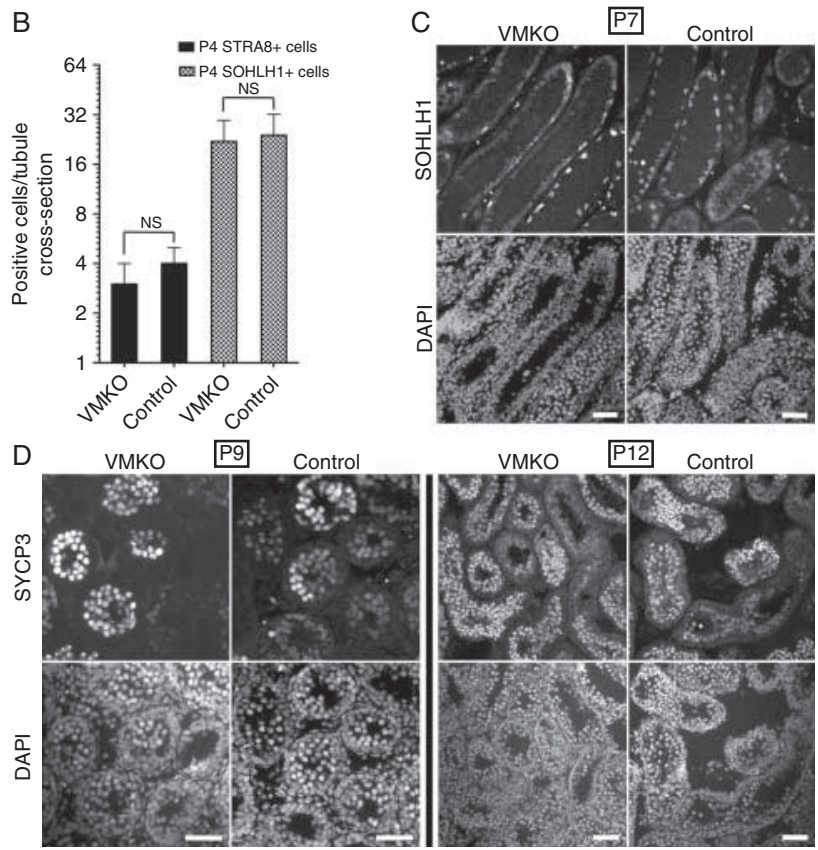

Figure 4 Neonatal and juvenile VMKO testes contain normal numbers of retinoic-acid-responsive germ cells. (A) Cross-sections of 2-day-old (P2, left) and P4 (right) VMKO and control testes immunostained for STRA8 (top) and exposed to DAPI (bottom). Arrows identify STRA8-positive cells. Scale bars $=50 \mu \mathrm{m}$. (B) Quantitation of STRA8+ (P4 testis) and SOHLH1 + (P7 testis) cells per cross-section of seminiferous tubule in VMKO and control testes. Graph exhibits mean values \pm S.E.M. Differences are not statistically significant (NS, Student's $t$-test). (C) Cross-sections of P7 VMKO and control testes immunostained for SOHLH1 (top) and exposed to DAPI (bottom). Scale bars $=50 \mu \mathrm{m}$. (D) Cross-sections of P9 (left) and P12 (right) VMKO and control testes immunostained for SYCP3 (top) and exposed to DAPI (bottom). Scale bars $=50 \mu \mathrm{m}$.

the P7 chromosome spreads was calculated, the values were statistically similar between $\mathrm{VMKO}$ and control samples (Fig. 5C). We determined the ratios of preleptotene, leptotene, and zygotene spermatocytes in P7 chromosome spreads and found that VMKO samples had fewer pre-leptotene and more zygotene spermatocytes when compared with controls (Fig. 5D). P14 chromosome spreads exhibited an even greater difference in the ratios. While significantly fewer VMKO spermatocytes were in pre-leptonema, leptonema, and zygonema at this time point, over twice as many VMKO cells were in pachynema when compared with control samples (Fig. 5E). $\gamma \mathrm{H} 2 \mathrm{AX}$ exhibits broad chromosomal distribution in leptotene and zygotene spermatocytes, but preferentially localizes to the sex chromosomes by the early-pachytene stage, appearing as a concentrated focus of immunostaining in nuclei (Fernandez-Capetillo et al. 2003). To assess whether pachytene spermatocytes were overrepresented in the meiotic cell populations of VMKO testes between P14 and adulthood, we examined the cross-sections of testis at P28 and observed that the majority of $\gamma \mathrm{H} 2 \mathrm{AX}$ in VMKO samples appeared as concentrated foci (Fig. 6A). The control sections, by contrast, contained many germ cells in which $\gamma \mathrm{H} 2 \mathrm{AX}$

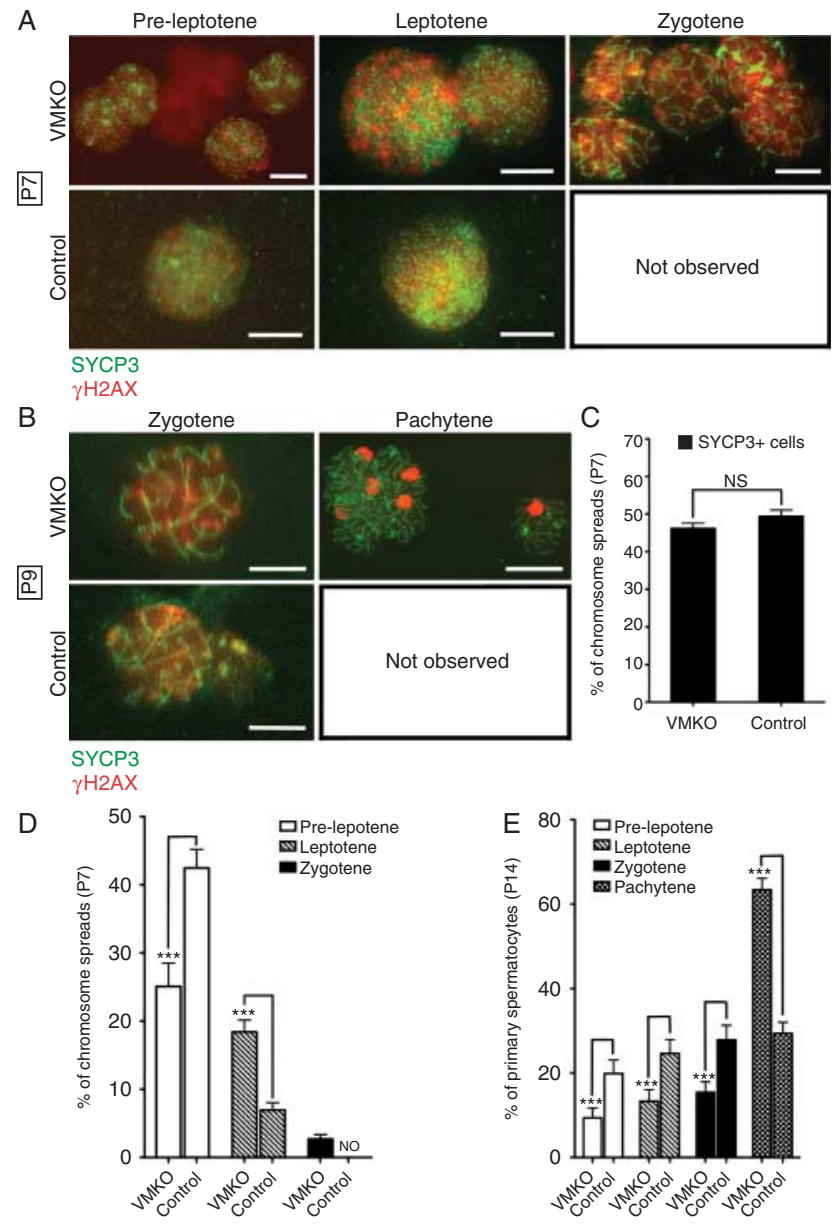

Figure $5 \mathrm{VMKO}$ male germ cells prematurely enter zygonema and pachynema in the first meiotic prophase. (A and B) Meiotic chromosome spreads were prepared from P7 (A) and P9 (B) VMKO and control testes and immunostained for SYCP3 (green) and $\gamma \mathrm{H} 2 \mathrm{AX}$ (red). Representative images are shown for all observed meiotic stages. Scale bars $=10 \mu \mathrm{M}$. (C) Quantification of the percentage of P7 cells in the chromosome spreads that were SYCP3 positive. Difference is not statistically significant (NS, Student's t-test). (D and E) Quantification of the percentage of P7 (D) and P14 (E) cells in the chromosome spreads that were pre-leptotene, leptotene, zygotene, and pachytene.

$* * * P<0.001$; statistical significance calculated using Student's $t$-test. $\mathrm{NO}$, not observed. All graphs exhibit mean values \pm S.E.M. 


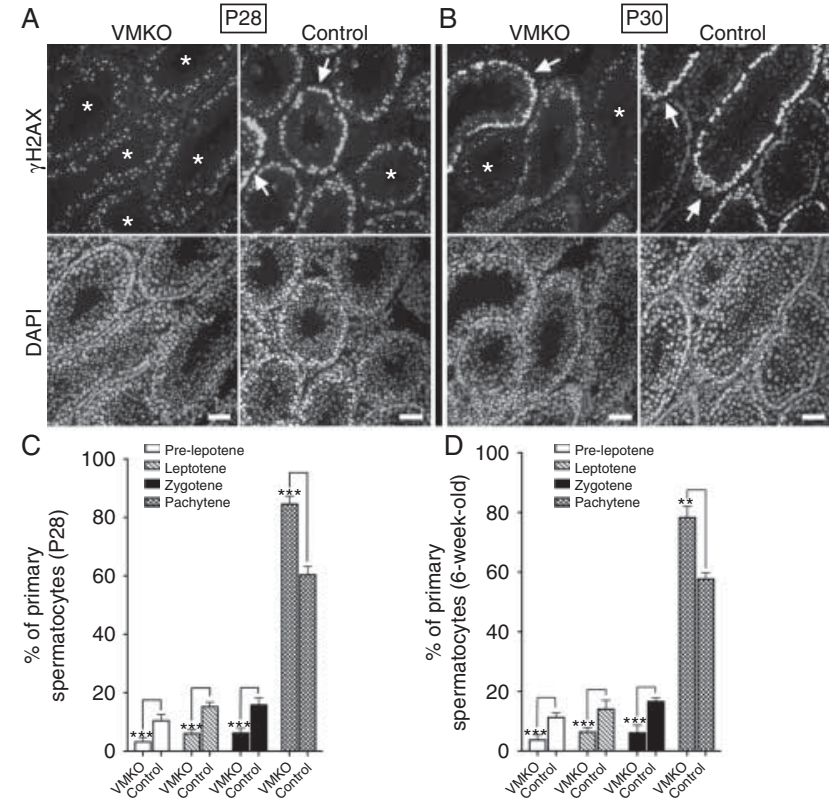

Figure 6 VMKO testes exhibit a higher proportion of pachytene cells relative to other meiotic stages. (A and B) Cross-sections of P28 (A) and P30 (B) VMKO and control testes immunostained for $\gamma \mathrm{H} 2 \mathrm{AX}$ (top) and exposed to DAPI (bottom). Asterisks demarcate seminiferous tubules enriched with pachytene cells (concentrated foci of $\gamma \mathrm{H} 2 \mathrm{AX}$ ). Arrows identify leptotene and zygotene spermatocytes. Scale bars $=50 \mu \mathrm{m}$. (C and D) Quantification of the percentage of P28 (C) and 6-week-old (D) cells in the chromosome spreads that were pre-leptotene, leptotene, zygotene, and pachytene. ${ }^{* *} P<0.01$ and ${ }^{* * *} P<0.001$; statistical significance calculated using Student's $t$-test. Graphs exhibit mean values \pm s.E.M.

exhibited broad nuclear distribution, indicative of leptotene and zygotene spermatocytes. This pattern was also seen at P30 (Fig. 6B) and in 6-week-old testes (data not shown). Chromosome spreads from P28 testes revealed that, like in P14 testes, more VMKO spermatocytes were in pachynema when compared with control cells (Fig. 6C). This pattern persisted in 6-week-old testes, with greater numbers of pachytene spermatocytes and fewer numbers of pre-leptotene, leptotene, and zygotene spermatocytes in VMKO testes when compared with controls (Fig. 6D). Finally, to determine whether post-meiotic germ cell development exhibits normal initiation in VMKO testes, we evaluated the distribution of the RNA-binding protein BOULE, which is essential for round spermatids to begin the elongation process (VanGompel \& Xu 2010). Adult VMKO germ cells exhibited normal BOULE distribution (Fig. 7), suggesting that the initial stages of spermiogenesis are not disrupted by an overrepresentation of pachytene spermatocytes in the meiotic cell population.

\section{Discussion}

In this study, we have described a role for MED1 in regulating the temporal progression of primary spermatocytes through meiosis. Med1-depleted germ cells prematurely appear in zygonema and pachynema during the initial wave of spermatogenesis, with a reduced proportion of cells remaining in pre-leptonema and leptonema. Once formed, pachytene cells lacking Med1 progress with temporal dynamics that result in a meiotic exit comparable with control cells. Subsequent spermatogenic waves retain this pattern of prolonged pachynema relative to other stages of the first meiotic prophase. Ultimately, fertility is normal in Med1 conditional knockout males, resulting in normal numbers of offspring.

The role MED1 plays in enhancing transcription in vivo from nuclear hormone receptors, including VDR, estrogen receptors, and peroxisome proliferatoractivated receptors, is well described (Oda et al. 2003, Jia et al. 2004, Zhang et al. 2005). While MED1 physically interacts with RARs, a functional role for a MED1-RAR interaction in vivo has not been shown. One study found that a human promyelocytic leukemia cell line was resistant to RA-induced differentiation in vitro following transient Med1 knockdown (Urahama et al. 2005). RA is the main driver of meiotic entry in germ cells (Griswold et al. 2012). While loss of Med1 does not inhibit spermatogonial differentiation or entry into meiosis, the Med1 loss-of-function effect alters the timing of meiotic progression once cells have committed to this process. It is important to note that MED1 interacts with members from other classes of transcription factors, including the GATA family (Crawford et al. 2002). Thus, it is possible that MED1 regulates transcription in developing germ cells through a nonhormone receptor or another previously unidentified binding partner.

Several other factors have been shown to play a role in the temporal progression of meiosis. Insulin-like factor 6 is essential for late pachynema of prophase I, with few germ cells differentiating beyond this stage in its absence (Burnicka-Turek et al. 2009). Loss of Dicer 1 in the male
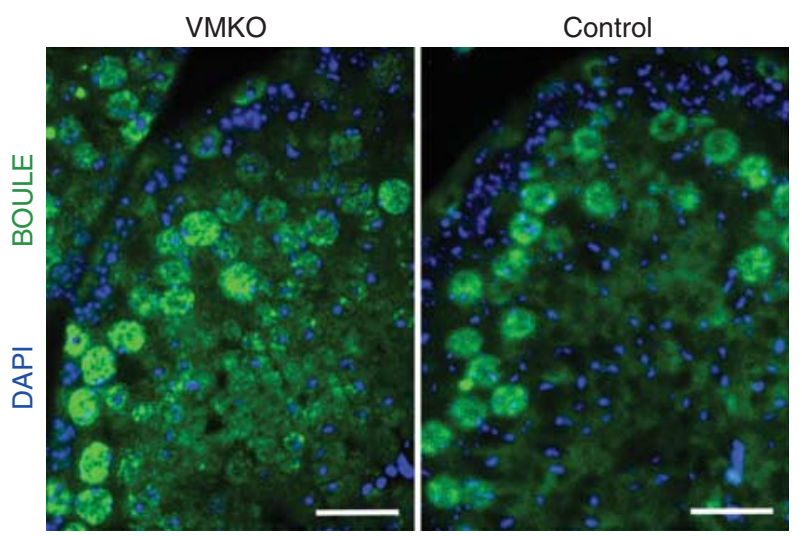

Figure $7 \mathrm{VMKO}$ testes exhibit normal post-meiotic germ cell development. Cross-sections of 6-week-old VMKO (left) and control (right) testes immunostained for BOULE (green) and exposed to DAPI (blue). Scale bars $=25 \mu \mathrm{m}$. 
germline results in a higher proportion of leptotene and zygotene cells and a reduced proportion of pachytene, diplotene, and metaphase I cells (Romero et al. 2011, Greenlee et al. 2012). Claudin 3 knockdown in the testis, meanwhile, generates meiotic cells that exhibit a prolonged preleptonema with respect to other stages in meiosis (Chihara et al. 2013). In light of these previous findings, MED1 could mediate its activity in the spermatocytes downstream of growth factor secretion, tight junction formation, or noncoding RNA production. The mechanism of how MED1 regulates meiotic progression remains to be defined in further detail.

The spermatogenic process relies on a high level of coordination between many different cell types. While RA and other extrinsic signaling molecules play key roles influencing spermatogonial differentiation and meiosis, the effects of these molecules are ultimately regulated within the germ cells themselves. In this study, we describe a role for MED1 in the regulation of meiotic progression in male germ cells. Together with other transcriptional and epigenetic regulators, MED1 appears to modulate the influence of extrinsic signaling factors on germ cells to correctly time key events during spermatogenesis.

\section{Declaration of interest}

The authors declare that there is no conflict of interest that could be perceived as prejudicing the impartiality of the research reported.

\section{Funding}

The authors gratefully acknowledge the Children's Research Fund of the Ann \& Robert H. Lurie Children's Hospital of Chicago and the Stanley Manne Children's Research Institute for its generous financial support to J M Huszar (Outstanding Graduate Student Award) and C J Payne (Institutional Funds). C J Payne is the recipient of an NIH Pathway-to-Independence Award from the Eunice Kennedy Shriver National Institute of Child Health and Human Development (R00 HD055330).

\section{References}

Ashley T 2004 The mouse "tool box" for meiotic studies. Cytogenetic and Genome Research 105 166-171. (doi:10.1159/000078186)

Ballow D, Meistrich ML, Matzuk M \& Rajkovic A 2006 Sohlh1 is essential for spermatogonial differentiation. Developmental Biology 294 161-167. (doi:10.1016/j.ydbio.2006.02.027)

Barrios F, Filipponi D, Pellegrini M, Paronetto MP, Di Siena S, Geremia R, Rossi P, De Felici M, Jannini EA \& Dolci S 2010 Opposing effects of retinoic acid and FGF9 on Nanos2 expression and meiotic entry of mouse germ cells. Journal of Cell Science 123 871-880. (doi:10.1242/jcs.057968)

Burnicka-Turek O, Shirneshan K, Paprotta I, Grzmil P, Meinhardt A, Engel W \& Adham IM 2009 Inactivation of insulin-like factor 6 disrupts the progression of spermatogenesis at late meiotic prophase. Endocrinology 150 4348-4357. (doi:10.1210/en.2009-0201)

Busada JT, Kaye EP, Renegar RH \& Geyer CB 2014 Retinoic acid induces multiple hallmarks of the prospermatogonia-to-spermatogonia transition in the neonatal mouse. Biology of Reproduction 90 64. (doi:10.1095/ biolreprod.113.114645)
Chen W \& Roeder RG 2011 Mediator-dependent nuclear receptor function. Seminars in Cell \& Developmental Biology 22 749-758. (doi:10.1016/j. semcdb.2011.07.026)

Chihara M, Ikebuchi R, Otsuka S, Ichii O, Hashimoto Y, Suzuki A, Saga Y \& Kon Y 2013 Mice stage-specific claudin 3 expression regulates progression of meiosis in early stage spermatocytes. Biology of Reproduction 89 3. (doi:10.1095/biolreprod.113.107847)

Crawford SE, Qi C, Misra P, Stellmach V, Rao MS, Engel JD, Zhu Y \& Reddy JK 2002 Defects of the heart, eye, and megakaryocytes in peroxisome proliferator activator receptor-binding protein (PBP) null embryos implicate GATA family of transcription factors. Journal of Biolgical Chemistry 277 3585-3592. (doi:10.1074/jbc.M107995200)

Fernandez-Capetillo O, Mahadevaiah SK, Celeste A, Romanienko PJ, Camerini-Otero RD, Bonner WM, Manova K, Burgoyne P \& Nussenzweig A $2003 \mathrm{H} 2 \mathrm{AX}$ is required for chromatin remodeling and inactivation of sex chromosomes in male mouse meiosis. Developmental Cell 4 497-508. (doi:10.1016/S1534-5807(03)00093-5)

Gallardo T, Shirley L, John GB \& Castrillon DH 2007 Generation of a germ cell-specific mouse transgenic Cre line, Vasa-Cre. Genesis 45 413-417. (doi:10.1002/dvg.20310)

Gely-Pernot A, Raverdeau M, Celebi C, Dennefeld C, Feret B, Klopfenstein M, Yoshida S, Ghyselinck NB \& Mark M 2012 Spermatogonia differentiation requires retinoic acid receptor $\gamma$. Endocrinology 153 438-449. (doi:10.1210/en.2011-1102)

Greenlee AR, Shiao MS, Snyder E, Buaas FW, Gu T, Stearns TM, Sharma M, Murchison EP, Puente GC \& Braun RE 2012 Deregulated sex chromosome gene expression with male germ cell-specific loss of Dicer1. PLoS ONE 7 e46359. (doi:10.1371/journal.pone.0046359)

Griswold MD, Hogarth CA, Bowles J \& Koopman P 2012 Initiating meiosis: the case for retinoic acid. Biology of Reproduction 86 35. (doi:10.1095/ biolreprod.111.096610)

Howell JM, Thompson JN \& Pitt GA 1963 Histology of the lesions produced in the reproductive tract of animals fed a diet deficient in vitamin A alcohol but containing vitamin A acid. I. The male rat. Journal of Reproduction and Fertility 5 159-167. (doi:10.1530/jrf.0.0050159)

Huszar JM \& Payne CJ 2013 MicroRNA 146 (Mir146) modulates spermatogonial differentiation by retinoic acid in mice. Biology of Reproduction 88 15. (doi:10.1095/biolreprod.112.103747)

Ito M, Yuan CX, Okano HJ, Darnell RB \& Roeder RG 2000 Involvement of the TRAP220 component of the TRAP/SMCC coactivator complex in embryonic development and thyroid hormone action. Molecular Cell $\mathbf{5}$ 683-693. (doi:10.1016/S1097-2765(00)80247-6)

Jensen MB 2014 Vitamin D and male reproduction. Nature Reviews. Endocrinology 10 175-186. (doi:10.1038/nrendo.2013.262)

Jia Y, Qi C, Kashireddi P, Surapureddi S, Zhu YJ, Rao MS, Le Roith D, Chambon P, Gonzalez FJ \& Reddy JK 2004 Transcription coactivator PBP, the peroxisome proliferator-activated receptor (PPAR)-binding protein, is required for PPARalpha-regulated gene expression in liver. Journal of Biolgical Chemistry 279 24427-24434. (doi:10.1074/jbc.M402391200)

Jiang P, Hu Q, Ito M, Meyer S, Waltz S, Khan S, Roeder RG \& Zhang X 2010 Key roles for MED1 LxxLL motifs in pubertal mammary gland development and luminal-cell differentiation. PNAS 107 6765-6770. (doi:10.1073/pnas.1001814107)

Kinuta K, Tanaka H, Moriwake T, Aya K, Kato S \& Seino Y 2000 Vitamin D is an important factor in estrogen biosynthesis of both female and male gonads. Endocrinology 141 1317-1324. (doi:10.1210/endo.141.4.7403)

Kumar S, Cunningham TJ \& Duester G 2013 Resolving molecular events in the regulation of meiosis in male and female germ cells. Science Signaling 6 e25. (doi:10.1126/scisignal.2004530)

Oakberg EF 1956 A description of spermiogenesis in the mouse and its use in analysis of the cycle of the seminiferous epithelium and germ cell renewal. American Journal of Anatomy 99 391-413. (doi:10.1002/ aja.1000990303)

Oda Y, Sihlbom C, Chalkley RJ, Huang L, Rachez C, Chang CP, Burlingame AL, Freedman LP \& Bikle DD 2003 Two distinct coactivators, DRIP/mediator and SRC/p160, are differentially involved in vitamin $\mathrm{D}$ receptor transactivation during keratinocyte differentiation. Molecular Endocrinology 17 2329-2339. (doi:10.1210/me.2003-0063)

Oda Y, Hu L, Bul V, Elalieh H, Reddy JK \& Bikle DD 2012 Coactivator MED1 ablation in keratinocytes results in hair-cycling defects and epidermal alterations. Journal of Investigative Dermatology 132 1075-1083. (doi:10.1038/jid.2011.430) 
Perey B, Clermont Y \& Leblond CP 1961 The wave of the seminiferous epithelium in the rat. American Journal of Anatomy 108 47-77. (doi:10.1002/aja.1001080105)

Peters AH, Plug AW, van Vugt MJ \& de Boer P 1997 A drying-down technique for the spreading of mammalian meiocytes from the male and female germline. Chromosome Research 5 66-68. (doi:10.1023/ A:1018445520117)

Raverdeau M, Gely-Pernot A, Feret B, Dennefeld C, Benoit G, Davidson I, Chambon P, Mark M \& Ghyselinck NB 2012 Retinoic acid induces Sertoli cell paracrine signals for spermatogonia differentiation but cell autonomously drives spermatocyte meiosis. PNAS 109 16582-16587. (doi:10.1073/pnas.1214936109)

Ren Y, Behre E, Ren Z, Zhang J, Wang Q \& Fondell JD 2000 Specific structural motifs determine TRAP220 interactions with nuclear hormone receptors. Molecular and Cellular Biology 20 5433-5446. (doi:10.1128/ MCB.20.15.5433-5446.2000)

Romero Y, Meikar O, Papaioannou MD, Conne B, Grey C, Weier M, Pralong F, De Massy B, Kaessmann H, Vassalli JD et al. 2011 Dicer1 depletion in male germ cells leads to infertility due to cumulative meiotic and spermiogenic defects. PLOS ONE 6 e25241. (doi:10.1371/journal. pone.0025241)

Snyder EM, Small C \& Griswold MD 2010 Retinoic acid availability drives the asynchronous initiation of spermatogonial differentiation in the mouse. Biology of Reproduction 83 783-790. (doi:10.1095/biolreprod.110.085811)

Snyder EM, Davis JC, Zhou Q, Evanoff R \& Griswold MD 2011 Exposure to retinoic acid in the neonatal but not adult mouse results in synchronous spermatogenesis. Biology of Reproduction 84 886-893. (doi:10.1095/ biolreprod.110.089755)

Stumpf M, Yue X, Schmitz S, Luche H, Reddy JK \& Borggrefe T 2010 Specific erythroid-lineage defect in mice conditionally deficient for Mediator subunit Med1. PNAS 107 21541-21546. (doi:10.1073/pnas. 1005794107)

Suzuki H, Ahn HW, Chu T, Bowden W, Gassei K, Orwig K \& Rajkovic A 2012 SOHLH1 and SOHLH2 coordinate spermatogonial differentiation. Developmental Biology 361 301-312. (doi:10.1016/j.ydbio.2011.10.027)

Tanaka H, Pereira LA, Nozaki M, Tsuchida J, Sawada K, Mori H \& Nishimune Y 1997 A germ cell-specific nuclear antigen recognized by a monoclonal antibody raised against mouse testicular germ cells. International Journal of Andrology 20 361-366. (doi:10.1046/j.13652605.1998.00080.x)

Tedesco M, Desimio MG, Klinger FG, De Felici M \& Farini D 2013 Minimal concentrations of retinoic acid induce stimulation by retinoic acid 8 and promote entry into meiosis in isolated pregonadal and gonadal mouse primordial germ cells. Biology of Reproduction 88 145. (doi:10.1095/ biolreprod.112.106526)

Thompson JN, Howell JM \& Pitt GA 1964 Vitamin A and reproduction in rats. Proceedings of the Royal Society of London. Series B, Biological Sciences 159 510-535. (doi:10.1098/rspb.1964.0017)
Urahama N, Ito M, Sada A, Yakushijin K, Yamamoto K, Okamura A, Minagawa K, Hato A, Chihara K, Roeder RG et al. 2005 The role of transcriptional coactivator TRAP220 in myelomonocytic differentiation. Genes to Cells 10 1127-1137. (doi:10.1111/j.1365-2443.2005. 00906.x)

Van Pelt AM \& De Rooij DG 1990 The origin of the synchronization of the seminiferous epithelium in vitamin A-deficient rats after vitamin A replacement. Biology of Reproduction 42 677-682. (doi:10.1095/ biolreprod42.4.677)

VanGompel MJ \& Xu EY 2010 A novel requirement in mammalian spermatid differentiation for the DAZ-family protein Boule. Human Molecular Genetics 19 2360-2369. (doi:10.1093/hmg/ddq109)

Vernet N, Dennefeld C, Rochette-Egly C, Oulad-Abdelghani M, Chambon P, Ghyselinck NB \& Mark M 2006 Retinoic acid metabolism and signaling pathways in the adult and developing mouse testis. Endocrinology 147 96-110. (doi:10.1210/en.2005-0953)

Yuan CX, Ito M, Fondell JD, Fu ZY \& Roeder RG 1998 The TRAP220 component of a thyroid hormone receptor-associated protein (TRAP) coactivator complex interacts directly with nuclear receptors in a liganddependent fashion. PNAS 95 7939-7944. (doi:10.1073/pnas.95. 14.7939)

Zhang X, Krutchinsky A, Fukuda A, Chen W, Yamamura S, Chait BT \& Roeder RG 2005 MED1/TRAP220 exists predominantly in a TRAP/ mediator subpopulation enriched in RNA polymerase II and is required for ER-mediated transcription. Molecular Cell 19 89-100. (doi:10.1016/ j.molcel.2005.05.015)

Zhou Q, Nie R, Li Y, Friel P, Mitchell D, Hess RA, Small C \& Griswold MD 2008 Expression of stimulated by retinoic acid gene 8 (Stra8) in spermatogenic cells induced by retinoic acid: an in vivo study in vitamin A-sufficient postnatal murine testes. Biology of Reproduction 79 35-42. (doi:10.1095/biolreprod.107.066795)

Zhu Y, Qi C, Jain S, Rao MS \& Reddy JK 1997 Isolation and characterization of PBP, a protein that interacts with peroxisome proliferator-activated receptor. Journal of Biolgical Chemistry 272 25500-25506. (doi:10.1074/jbc.272.41.25500)

Zhu Y, Qi C, Jia Y, Nye JS, Rao MS \& Reddy JK 2000 Deletion of PBP/PPARBP, the gene for nuclear receptor coactivator peroxisome proliferator-activated receptor-binding protein, results in embryonic lethality. Journal of Biolgical Chemistry 275 14779-14782. (doi:10.1074/jbc.C000121200)

Received 17 September 2014

First decision 13 October 2014

Revised manuscript received 11 March 2015

Accepted 16 March 2015 